\title{
A murine model of hereditary hemorrhagic telangiectasia
}

\author{
Annie Bourdeau, ${ }^{1}$ Daniel J. Dumont, ${ }^{2}$ and Michelle Letarte ${ }^{1}$ \\ ${ }^{1}$ Cancer and Blood Program, The Hospital for Sick Children and Department of Immunology, University of Toronto, \\ Toronto, Ontario M5G 1X8, Canada \\ ${ }^{2}$ Division of Cancer Biology Research, Sunnybrook and Women's College Health Sciences Center, and \\ Department of Medical Biophysics, University of Toronto, Toronto, Ontario M4N 3M5, Canada \\ Address correspondence to: Michelle Letarte, Cancer and Blood Program, The Hospital for Sick Children, \\ 555 University Avenue, Toronto, Ontario M5G 1X8, Canada. \\ Phone: (416) 813-6258; Fax: (416) 813-6255; E-mail: mablab@sickkids.on.ca.
}

Received for publication August 9, 1999, and accepted in revised form September 22, 1999.

Endoglin (CD105), an accessory protein of the TGF- $\beta$ receptor superfamily, is highly expressed on endothelial cells. Hereditary hemorrhagic telangiectasia type 1 (HHT1) is associated with mutations in the Endoglin gene, leading to haploinsufficiency. To generate a disease model and ascertain the role of endoglin in development, we generated mice lacking 1 or both copies of the gene. Endoglin null embryos die at gestational day 10.0-10.5 due to defects in vessel and heart development. Vessel formation appears normal until hemorrhage occurs in yolk sacs and embryos. The primitive vascular plexus of the yolk sac fails to mature into defined vessels, and vascular channels dilate and rupture. Internal bleeding is seen in the peritoneal cavity, implying fragile vessels. Heart development is arrested at day 9.0, and the atrioventricular canal endocardium fails to undergo mesenchymal transformation and cushion-tissue formation. These data suggest that endoglin is critical for both angiogenesis and heart valve formation. Some heterozygotes, either with an inbred 129/Ola or mixed C57BL/6-129/Ola background, show signs of HHT, such as telangiectases or recurrent nosebleeds. In this murine model of HHT, it appears that epigenetic factors and modifier genes, some of which are present in 129/Ola, contribute to disease heterogeneity.

J. Clin. Invest. 104:1343-1351 (1999).

\section{Introduction}

Hereditary hemorrhagic telangiectasia (HHT) is an autosomal dominant vascular dysplasia that affects 1 in 10,000 individuals. It is heterogeneous both between and within families in age of onset and severity of clinical manifestations (1). The first symptom of HHT is generally epistaxis, whereas telangiectases are highly variable. Gastrointestinal bleeding usually occurs later in life, and $10-25 \%$ of patients develop life-threatening complications such as pulmonary or cerebral arteriovenous malformations (AVMs). This heterogeneity has been explained in part by the identification of 2 distinct genes. Endoglin (End) is mutated in HHT1 (2) and is associated with a higher incidence of pulmonary AVMs than HHT2, a milder form of the disease with a later onset; HHT2 is the result of mutations in the ALK-1 gene (3-7). We have shown that mutated endoglin is expressed rarely in HHT1 patients, and, when present, it is found exclusively as an intracellular species (8). The normal copy of endoglin is expressed at the cell surface at levels half of normal, suggesting that haploinsufficiency is responsible for $\operatorname{HHT} 1(8,9)$.

Human endoglin (CD105) is a homodimeric transmembrane glycoprotein constitutively expressed at high levels on endothelial cells of capillaries, veins, and arteries $(10,11)$. Murine endoglin is found on all endothelial cells and on mesenchymal stromal cells in several tissues (12). Endoglin binds TGF- $\beta_{1}$ and TGF- $\beta_{3}$ through its association with TGF- $\beta$ receptor II (T $\beta$ RII) (13-15) and modulates several responses to TGF- $\beta_{1}(16,17)$. It also binds activin, BMP-7, and BMP-2 by interacting with their respective ligand-binding receptors, suggesting that it is in the receptor complex for several growth factors of the TGF- $\beta$ superfamily (15).

We report here that deficiency in endoglin causes vascular and cardiovascular defects leading to embryonic lethality. Mice heterozygous for the mutation develop normally. However, some heterozygotes show clinical signs of HHT, providing the first animal model of HHT1.

\section{Methods}

Generation of End-deficient mice. A murine endoglin genomic clone of $14.8 \mathrm{~kb}$ was isolated from a $129 \mathrm{SVJ}$ library by screening with the nonradioactive dioxigenin (DIG)-system (Boehringer-Mannheim, Montreal, Quebec, Canada) with a full-length and a 5 '-end fragment (583 bp) of murine endoglin cDNA (12). The replacement targeting vector was engineered in 3 cloning steps and required the pSDKLacZ vector with a $L a c Z$ cassette and the pPNT vector with neomycin (Neo) and herpes simplex thymidine kinase $(t k)$ cassettes for positive and negative selections. A 1426-bp SmaI endoglin fragment, containing the promoter area and terminating $8 \mathrm{bp}$ upstream of the ATG, was used as $5^{\prime}$ homology region $\left(5^{\prime}\right.$ HR) and subcloned upstream of the $L a c Z$ cassette into the PSDKLacZ vector. A SmaI-BglII fragment (5100 bp of intron 1) was used as $3^{\prime} \mathrm{HR}$ and ligated into the blunted XbaI (BamHI cohesive) site of the PPNT vector, upstream 
of the tk cassette. The $5^{\prime} \mathrm{HR}$ and $L a c Z$ cassette were then inserted as a SalI fragment into the $X h o I$ site, upstream of the Neo cassette in the pPNT vector. The LacZ and Neo genes thus replaced a region of $609 \mathrm{bp}$ containing the End initiation codon.

The endoglin-targeting construct was linearized with NotI and electroporated into the 129/Ola-derived embryonic stem (ES) cell line E14. Colonies were subjected to positive and negative selections with G418 and ganciclovir $(2 \mu \mathrm{M} / \mathrm{mL})$ for 10 days. DNA was made from all resistant ES cell clones and digested with ScaI. Screening for proper recombination events was achieved by Southern blot analysis using a ${ }^{32} \mathrm{P}$-labeled $5^{\prime}$ external probe (614-bp SmaI fragment) and a 1000-bp EcoRI-SacI LacZ internal probe to confirm single integration events (Figure 1a). Positive ES cell clones were injected into C57BL/6 blastocysts yielding 4 fertile male chimeras, 2 of which gave germline transmission.

The first generation $\left(\mathrm{F}_{1}\right)$ of $E n d^{+/-}$mice was produced by mating the chimeras with wild-type C57BL/6 females (Taconic Farms, Germantown, New York, USA). Eight $F_{1}$ $\mathrm{C} 57 \mathrm{BL} / 6 \mathrm{End}^{+/-}$males were crossed with wild-type or $\mathrm{C} 57 \mathrm{BL} / 6 \mathrm{End}^{+/-}$females for 4 generations. These $\mathrm{F}_{1}-\mathrm{F}_{4}$ mice have a mixed genome of C57BL/6 and 129/Ola. The phenotype of $E$ nd ${ }^{-/}$embryos was analyzed on $\mathrm{F}_{1}$ and $\mathrm{F}_{2}$ intercrosses between C57BL/6 End ${ }^{+/-}$mice. $\mathrm{F}_{1} \mathrm{C} 57 \mathrm{BL} / 6 \mathrm{End}^{+/-}$ were also crossed with wild-type CD1 mice (Harlan Sprague Dawley, Indianapolis, Indiana, USA). These mice, with a mixture of CD1, C57BL/6, and 129/Ola genes, were maintained by backcrosses with wild-type CD1 for 3 generations. End $^{+/-}$mice have also been generated on an inbred 129/Ola background (same strain as ES cells) by mating of the chimeras with wild-type 129/Ola (Harlan UK, Bicester, United Kingdom) and subsequent backcrossing for 2 generations. All studies were approved by the Ontario Cancer Institute Animal Care Committee.

Genotyping of mice. The mid-day of plug observation was counted as E0.5. Embryos of equivalent stage and generally from the same litter were used for comparative analyses. Genotypes of embryos were determined using DNA isolated from the yolk sac or a small piece of embryonic tissue; for postnatal DNA, tails were used. A multiplex PCR was designed to amplify 3 sets of primers in a single reaction that can distinguish $E n d^{+/+}, E_{n}{ }^{+/-}$, and $E n d^{-/-}$alleles. All PCR reactions were run with initial denaturation for 2 minutes at $94^{\circ} \mathrm{C}$, followed by 30 cycles at $94^{\circ} \mathrm{C}$ for $30 \mathrm{sec}-$

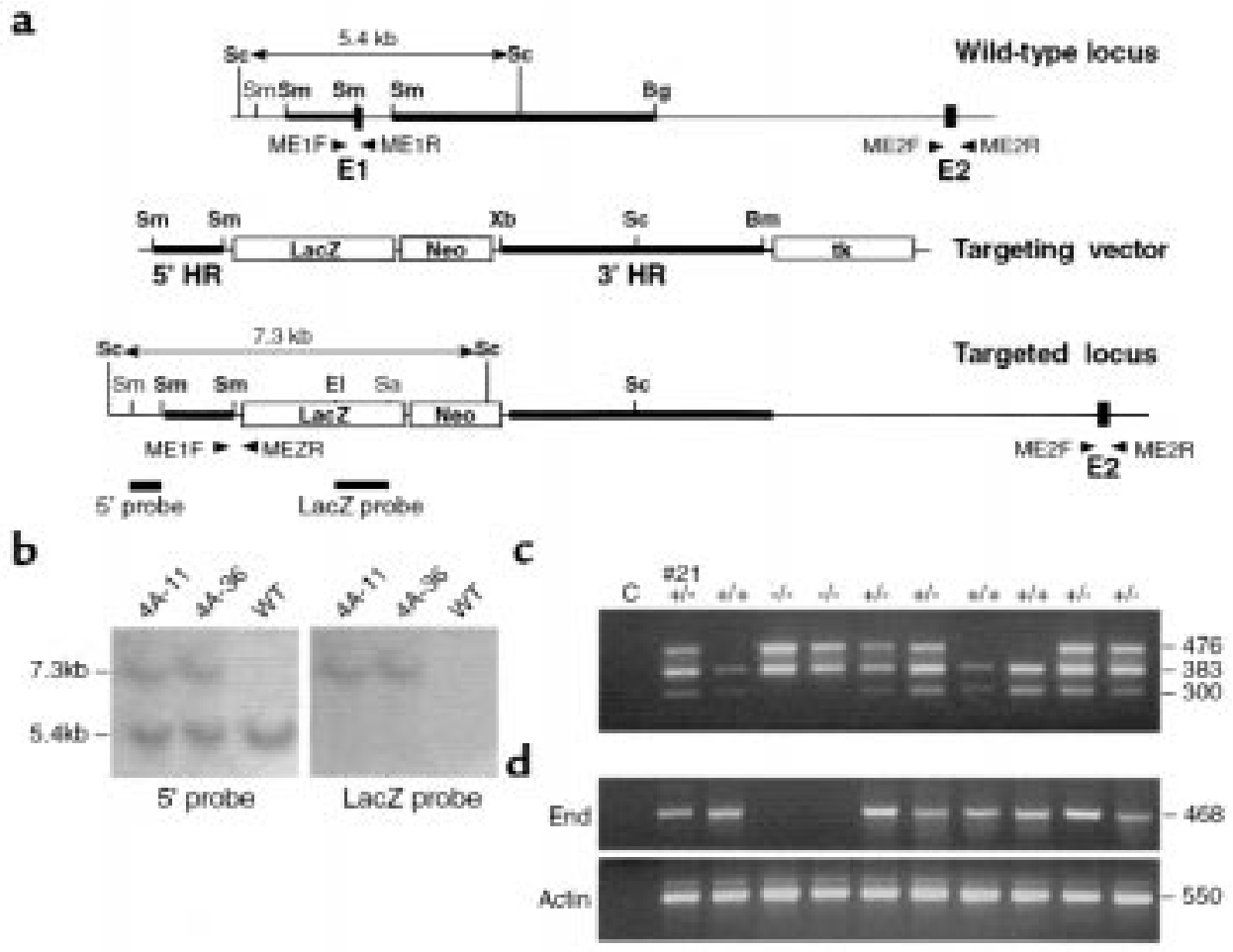

Figure 1

Generation of End ${ }^{-/-}$mice. (a) Targeting strategy. Homologous recombination deletes 609 bp of the End gene including exon 1 (E1; 66 bp), placing the LacZ gene under control of its promoter. The targeting construct contains a 1.4-kb Smal fragment ( $\left.5^{\prime} \mathrm{HR}\right)$ and a 5.1-kb Smal-Bg/ll fragment ( $3^{\prime} \mathrm{HR}$ ) of the End gene flanking the LacZ-Neo cassette. Proper recombination events were screened by Southern blot analysis with $5^{\prime}$ external and LacZ internal probes. Bm, BamHI; Bg, BgllI; El, EcoRI; Sa, Sacl; Sc, Scal; Sm, Smal; Xb, Xbal. (b) Identification of targeted ES cell lines. DNA from 2 geneticin- and ganciclovir-resistant targeted ES cells (4A-11, 4A-36) and a wild-type clone (WT) were digested with Scal. The 5.4-kb WT and $7.3-\mathrm{kb}$ recombinant alleles hybridizing with the $5^{\prime}$ external probe and the recombinant allele reacting with the LacZ probe are shown. (c) Genotyping of embryos by multiplex PCR. DNA from yolk sacs of an E9.5 litter derived from a C57BL/6 End +- mating is shown; \#21 represents the mother and $C$ represents the PCR control reaction without DNA. Primers ME1F and ME1R amplify normal exon 1 (300 bp), ME2F and ME2R amplify normal exon 2 (383 bp), and ME1F and MEZR specifically amplify the recombinant product (476 bp). (d) Absence of endoglin mRNA in End ${ }^{-/}$embryos. RNA was prepared from the same embryos as in $\mathbf{c}$ and analyzed for endoglin and $\beta$-actin mRNA by RT-PCR. 
onds, $56^{\circ} \mathrm{C}$ for 35 seconds, and $68^{\circ} \mathrm{C}$ for 2.5 minutes, with a final extension at $68^{\circ} \mathrm{C}$ for 5 minutes. Reactions contained 300 ng DNA, $400 \mu \mathrm{M}$ dNTP, $2.5 \mathrm{mM}$ magnesium chloride $\left(\mathrm{MgCl}_{2}\right), 1 \mathrm{U}$ AmpliTaq DNA Polymerase (Perkin Elmer, Roche Molecular Systems, Branchburg, New Jersey, USA), 40 pmol of primers ME1F and MEZR, and 20 pmol of the others. Selected primers, $5^{\prime} \rightarrow 3^{\prime}$, were: ME1F (TACCTCTGGATACCGGATAAG), ME1R (AAGTTTGGCATCCTATGAAAC), MEZR (AAATGTGAGCGAGTAACAACC), ME2F (ATCTTACCCACTGAGCCATCT), and ME2R (CCCAGTCTACTCCGATTCTTA).

RT-PCR. RNA was extracted from E9.5 embryos using TRIzol Reagent (GIBCO BRL, Mississauga, Ontario, Canada), and $1 \mu \mathrm{g}$ was used for cDNA synthesis using Superscript RT (GIBCO BRL). The cDNA was amplified for $\beta$-actin and endoglin using reported primers (12). PCR conditions were similar to those used above, except for 30 cycles of extension at $72^{\circ} \mathrm{C}$ for 30 seconds, and a final one of 5 minutes, using $1.5 \mathrm{mM} \mathrm{MgCl}_{2}$ and $200 \mu \mathrm{M} \mathrm{dNTP}$.

Whole-mount $\beta$-galactosidase ( $\beta$-gal) staining. Embryos or yolk sacs were dissected in PBS, fixed and stained as described (18), except for postfixation in $10 \%$ formaldehyde (Fisher Scientific Co., Nepean, Ontario, Canada). The embryos were paraffin embedded, sectioned (7-10 $\mu \mathrm{m})$, and counterstained with $0.1 \%$ nuclear fast red (Fluka Chemica, Oakville, Ontario, Canada). Images were acquired with an Olympus BX50 microscope linked to a CCD video camera (Carsen Medical Scientific, Markham, Ontario, Canada) and digitized on a Power Macintosh G3 computer.

\section{Results}

Generation of endoglin null mice. A targeting construct was engineered to delete End exon 1 and its initiation codon, replacing it with the LacZ-Neo cassette (Figure 1a). Using Southern blot analysis, 8 heterozygous $\left(\mathrm{End}^{+/-}\right)$ES cell clones were identified, yielding a recombination frequency of $1 / 30$. Results obtained for the 2 ES cell clones that gave germ-line transmission, $4 \mathrm{~A}-11$ and $4 \mathrm{~A}-36$, are illustrated in Figure 1b.

Embryos obtained from matings of C57BL/6 End $\mathrm{En}^{+/}$ mice were genotyped by multiplex PCR. Results from typing of an E9.5 litter are shown in Figure 1c. Two End $-{ }_{--}$endoglin embryos expressed the 476-bp fragment of the recombinant allele and the 383-bp fragment from normal exon 2 . Three wild-type $\left(\right.$ End $\left.^{+/+}\right)$embryos showed the normal PCR products for exon 1 (300 bp) and exon 2 (383 bp). Four End ${ }^{+/-}$embryos and the End ${ }^{+/-}$mother (\#21) showed all 3 PCR products.

To verify that the targeted mutation inactivated the gene, we examined expression of End mRNA in the embryos analyzed in Figure 1c. The 468-bp product corresponding to murine endoglin (exons 7-10) was present in the $E n d^{+/-}$and $E n d^{+/+}$embryos, but absent from the 2 End ${ }^{-/-}$embryos. $\beta$-actin (550 bp) was expressed at equivalent levels in all embryos. Thus, no wild-type or truncated endoglin mRNA was detectable in End ${ }^{-/-}$mice (Figure 1d).

End ${ }^{-/}$mice die in utero at E10-10.5. Expression of $\beta$-gal, under the control of the endoglin promoter in the tar- geting vector, recapitulated endogenous expression of endoglin in $E n d^{+/-}$mice and facilitated the analysis of the End ${ }^{-/-}$phenotype in embryos. Examination of 103 E7.5-8.5 live embryos from C57BL/ $6 \mathrm{End}^{+/-}$intercrosses revealed no obvious embryonic, placental, or yolk sac abnormalities and a normal 1:2:1 Mendelian ratio (Table 1). At E9.0, End ${ }^{+/-}$and End ${ }^{-/-}$embryos were of similar size, and their vasculature was revealed by the staining associated with endothelial cells. The heart of several End ${ }^{-/-}$ embryos appeared enlarged (Figure 2). At E9.5 the End ${ }^{-/-}$ embryos showed signs of growth retardation featured by a smaller head, underdeveloped nasal processes, and branchial arches. The heart was still beating but edematous pericardium was seen (Figure 2). At E9.0-9.5, 99 live embryos gave a normal Mendelian ratio. Of the 40 embryos analyzed at E10-10.5, only 7 were End ${ }^{-/-} ; 6$ were dead with collapsed vasculature, edemic heart, and exten-
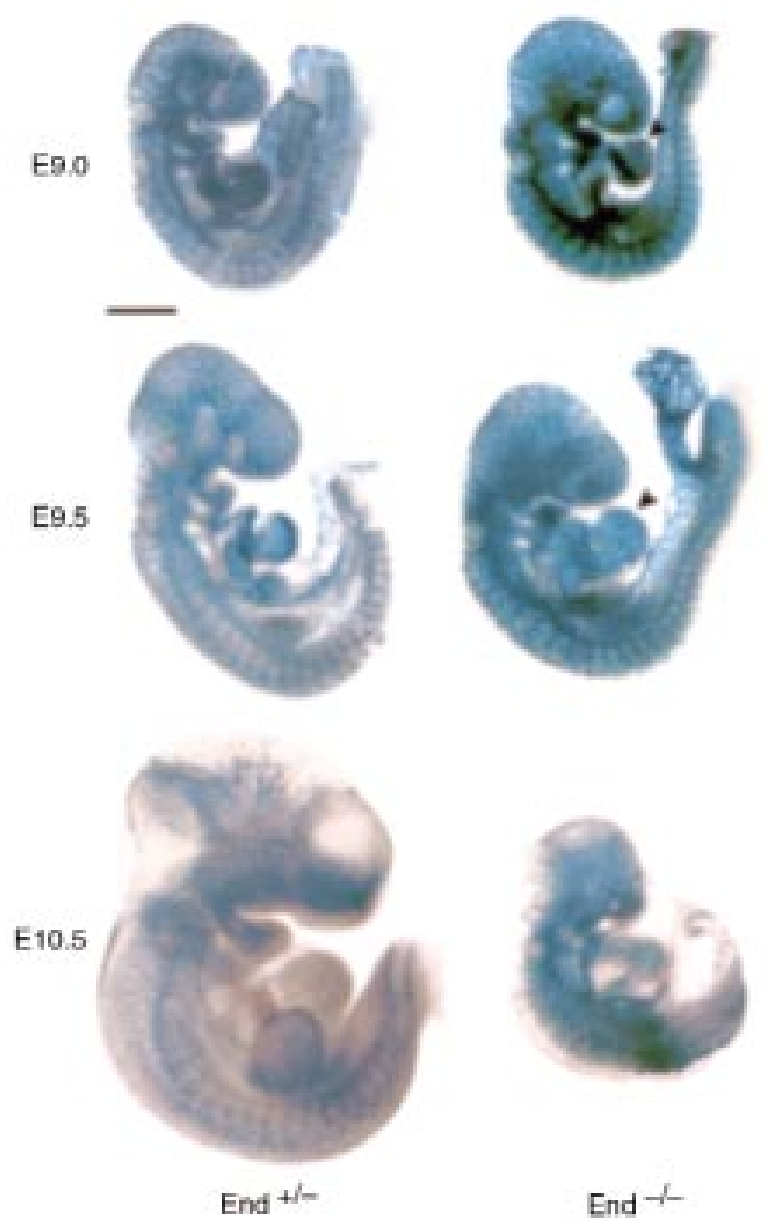

Figure 2

Arrest in development in End-1- embryos. $\beta$-gal expression driven by the End promoter was analyzed in whole End ${ }^{+/-}$and End-1- embryos. At E9.0, embryos are of similar size and their vasculature appears normal. The End ${ }^{-/}$embryo shows an enlarged heart protruding forward (arrowhead). At E9.5, edematous pericardium (arrowhead) is observed in the End ${ }^{-/}$embryo, which is growth-retarded compared with the End ${ }^{+/-}$embryo. At E10.5, the End ${ }^{-/-}$embryo is dead and is much smaller that the End ${ }^{+/-}$embryo. Bar: $500 \mu \mathrm{m}$. 
Table 1

Genotype of offspring from C57BL/6 End ${ }^{+/-}$matings

$\begin{array}{lccccc}\text { Day of gestation } & \text { Total embryos } & \text { End }^{+/+} & \text {End }^{+/-} & \text {End } & \text { Resorbed } \\ \text { 7.5-8.5 } & 108 & 25 & 50 & 28 & 5 \\ 9.0-9.5 & 107 & 23 & 49 & 27 & 8 \\ 10.0-10.5 & 40 & 13 & 20 & 7^{\text {A }} & 0 \\ 11.5-15.5 & 30 & 9 & 17 & 0 & 4 \\ \text { Adults } & 136 & 43 & 89 & 0 & 4^{\text {B }}\end{array}$

${ }^{A} 6$ of 7 embryos were present but dead. ${ }^{B}$ Mice who died of unrelated causes, between 1-3 months.

sive tissue necrosis, and 1 showed irregular heart beats and extensive edema (Figure 2 and Table 1). From E11.5 to 15.5 , no End ${ }^{-/}$embryos were found among 30, confirming that deficiency in endoglin leads to embryonic lethality at E10-10.5 (Table 1). From a total of 136 born offspring, 33\% were wild-type $\left(\mathrm{End}^{+/+}\right)$, 67\% were $\mathrm{End}^{+/-}$, and none were homozygous (End ${ }^{-/}$), showing conclusively that the endoglin-null phenotype is lethal (Table 1).

Yolk sac defects in End ${ }^{-/}$mice. The primitive vasculature of the End ${ }^{-/}$embryos and the early vascular plexus of the yolk sac were normal until E9.0. This suggested a defect in yolk sac remodeling, essential for the interconnection of embryonic and extraembryonic circulatory systems. Yolk sacs of End ${ }^{-1-}$ embryos at E9.0-9.5 revealed an abnormal vascular plexus. At E9.0, vascular channels were numerous, lined with an intact endothelium, and filled with normal levels of primitive erythroblasts (Figure 3 , a and b). However, no branching occurred, in contrast to the End ${ }^{+/-}$yolk sac (Figure 3, c and d). At E9.5, vitelline vessels were completely absent from End $^{-/-}$yolk sacs (Figure 3, e and f) and were replaced by enlarged and leaky channels that released their content into the yolk sac cavity (Figure 3, g and h). This hemorrhage was evident in unstained embryos, which showed blood accumulating in the yolk sac cavity between the amnion and the yolk sac membranes (Figure 3, i and j). We conclude that in the absence of endoglin, primitive vascular channels of the yolk sac did not form large vessels and were susceptible to rupture releasing hematopoietic precursors into the yolk sac cavity.

Internal hemorrhage and abnormal heart development in End ${ }^{-/}$embryos. Direct microscopic examination of unstained whole embryos dissected away from the yolk $\mathrm{sac}$ at E9.0 revealed internal hemorrhages in $\mathrm{End}^{-/-}$ embryos (Figure 3, $\mathrm{k}$ and $\mathrm{l}$ ), suggesting that vascular defects were not limited to the extraembryonic vasculature. Histological sections of End ${ }^{-/}$embryos showed blood accumulating in the peritoneal cavity indicating that endothelium integrity was compromised. The dorsal aorta or the observed dilated umbilical vein could be the source of the extravasated blood (Figure 3, $m$ and $n$ ). Thus, in the absence of endoglin, embryonic vessels are more fragile and susceptible to rupture.

End ${ }^{-/-}$embryos harvested at E9.0-10.5 had enlarged hearts and showed edematous pericardium when compared with their $\mathrm{End}^{+/-}$littermates (Figure 2). Sagittal sections revealed major differences in heart development. Normal End $d^{+-}$embryos showed signs of a progressively developing endocardium, such as increasing trabeculation and closure of the atrioventricular canal (Figure 4). Endoglin expression, determined by $\beta$-gal activity, was also observed on cells undergoing endocardial-mesenchymal transformation and on the migrating mesenchymal cells that later form the atrioventricular cushion tissue (Figure 4). In contrast, the End ${ }^{-/-}$embryos manifested defects in heart development from E9.0. The endocardium remained rudimentary in the primitive ventricle, whose lumen failed to close in the atrioventricular area. At E9.0, some embryos revealed an abnormally dilated endocardium in the common atrial chamber and the bulbus cordis (Figure 4). No mesenchymal cells were detected in the heart of the End ${ }^{-/-}$embryos analyzed, indicating that endocardial-mesenchymal

Table 2

Clinical signs of $\mathrm{HHT}$ in End ${ }^{+/-}$mice

\begin{tabular}{|c|c|c|c|c|c|c|c|}
\hline \multirow[t]{2}{*}{ Mouse strain } & \multirow[t]{2}{*}{ Total no. } & \multicolumn{3}{|c|}{ Nosebleeds } & \multicolumn{3}{|c|}{ Telangiectases } \\
\hline & & No. of mice & $\begin{array}{c}\text { Age of } \\
\text { onset (wk) }\end{array}$ & $\begin{array}{c}\text { Frequency } \\
\text { (per wk) }\end{array}$ & No. of mice & Location & $\begin{array}{c}\text { Age of } \\
\text { onset (wk) }\end{array}$ \\
\hline C57BL/ 6 WT (dark coat color) & 45 & 0 & - & - & 0 & - & - \\
\hline C57BL/6 End ${ }^{+/-}$mixed 129/Ola $\left(\mathrm{F}_{1}-\mathrm{F}_{4}\right)$ & 227 & 4 & & & 14 & & \\
\hline Dark coat color ${ }^{A}$ & 207 & 1 & - & - & 1 & Ear & 23 \\
\hline Light coat color ${ }^{\mathrm{B}}$ & 20 & 3 & - & - & 13 & & \\
\hline female $\left(F_{3}, F_{4}\right)$ & 9 & 0 & - & - & 3 & Ear & $16-21$ \\
\hline CD1 WT (light coat color) & 20 & 0 & - & - & 0 & - & - \\
\hline CD1 End ${ }^{+/-}$mixed C57BL/6 $\left(\mathrm{F}_{1}-\mathrm{F}_{3}\right)$ & 51 & 0 & & & 0 & & \\
\hline Dark coat color & 19 & 0 & - & - & 0 & - & - \\
\hline Light coat color & 32 & 0 & - & - & 0 & - & - \\
\hline 129/Ola WT (light coat color) & 20 & 0 & - & - & 0 & - & - \\
\hline 129/Ola End + -(light coat color) & 10 & 3 & & & 5 & & \\
\hline male $55.5\left(\mathrm{~F}_{1}\right)$ & & & 12 & $2-3$ & & Ear, neck, tail & 12 \\
\hline female $70.3\left(F_{1}\right)$ & & & - & - & & Ear & 17 \\
\hline female $55.83\left(\mathrm{~F}_{1}\right)$ & & & - & - & & Ear & 27 \\
\hline female $102.6\left(F_{2}\right)$ & & & 2 & 2 & & Tail, ear & 1 \\
\hline
\end{tabular}

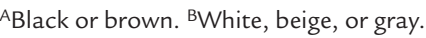




\section{Figure 3}

Vascular defects in End-1- mice. Whole-mount embryos in their yolk sacs were stained for $\beta$-gal activity. (a, b, e, and f) Direct microscopic examination of the yolk sacs. (c, $\mathbf{d}, \mathbf{g}$, and $\mathbf{h}$ ) Sagittal histological sections. At E9.0, the normal capillary plexus and initiation of branching are seen in the $E n d^{+/-}$embryo (a and c). The End ${ }^{-/-}$yolk sac also has a highly vascularized plexus, but no vessel branching is observed (b and d). At E9.5, a vitelline vessel ( $v$ ) is readily detectable in the End ${ }^{+/-}$yolk sac (e); this intact vessel is full of primitive red cells $(\mathbf{g})$. The End ${ }^{-1-}$ yolk sac shows a disorganized capillary plexus and no vitelline vessels (f); abnormally dilated blood islands are seen $(\mathbf{h})$, which have ruptured, releasing primitive erythroblasts toward the amnion (arrowhead). (i and j) Unstained E9.5 embryos, with yolk sac and placenta still attached. Bleeding in the yolk sac cavity (arrowhead) and edematous pericardium (arrow) are observed in End ${ }^{-/}$embryo (j), compared with a littermate control (i). An unstained E9.0 End $\mathrm{d}^{+/-}$embryo (k), dissected away from the yolk sac, is compared with an End-/- littermate (I), which shows internal bleeding (arrow). Sagittal sections stained for $\beta$-gal demonstrate the presence of blood (arrow) in the peritoneal cavity of the End ${ }^{-1-}$ embryo (n), which is absent from the End $^{+/-}$embryo (m). a, dorsal aorta; pc, peritoneal cavity; u, umbilical vein. Bar: $100 \mu \mathrm{m}(\mathbf{a}-\mathbf{h}), 500 \mu \mathrm{m}$ (i and j), $250 \mu \mathrm{m}(\mathbf{k}-\mathbf{n})$.

transformation, which leads to valve formation and heart septation, did not occur. At E10.5, the heart of the End $\mathrm{d}^{-/}$embryos was arrested, no longer beating, and with extensive necrosis.

End $^{+/-}$mice develop clinical signs of HHT. Four generations of C57BL/6 End ${ }^{+/-}$mice (a total of 227) were examined over a period of 1 to 12 months for clinical manifestations of HHT. Sick animals were first recognized by ruffled fur, weight loss, and visible ear telangiectases. We observed 14 affected $\mathrm{End}^{+/-}$mice, 13 of the 20 with a light coat color and only 1 of the 207 with a dark coat color (Table 2). Some animals also had neck and tail telangiectases and bled from the nose or mouth, once or twice a week (Table 2). Two mice died with extensive disease manifestations such as difficulty in breathing and internal hemorrhage. These $\mathrm{C} 57 \mathrm{BL} / 6$ End $^{+/-}$mice $\left(\mathrm{F}_{2}-\mathrm{F}_{4}\right)$ still have a mixed genetic background with 129/Ola, from which the light coat color is derived. To determine if the 129/Ola strain was associated with the disease phenotype, we generated End $^{+/-}$mice on this inbred background. We also bred the mixed C57BL/6-129/Ola F 1 to CD1 mice, also of light coat color.

None of the $51 \mathrm{End}^{+/-} \mathrm{CD} 1$ mice showed signs of disease when observed over 3-9 months. However, 5 out of $10 \mathrm{End}^{+/-}$inbred 129/Ola mice showed visible telangiectases on the ears and 3 had nosebleeds, when observed over a period of 7 months (Table 2). Male 55.5 had its first nosebleed at 7 weeks and thereafter at a frequency of 2-3 times per week. Dried blood was noticeable around the nose after each bleed (Figure 5). At the end of a bleeding episode spanning 18-24 hours, the hematocrit value was dramatically reduced relative to control mice ( 45 vs. 67), but was returned to normal 4 days later. Female 69.1 had nosebleeds at least once a week, starting at 10 weeks (Table 2). Its hematocrit measured on a day with epistaxis was comparable to that of a female control mouse (55 vs. 52). Hematocrit
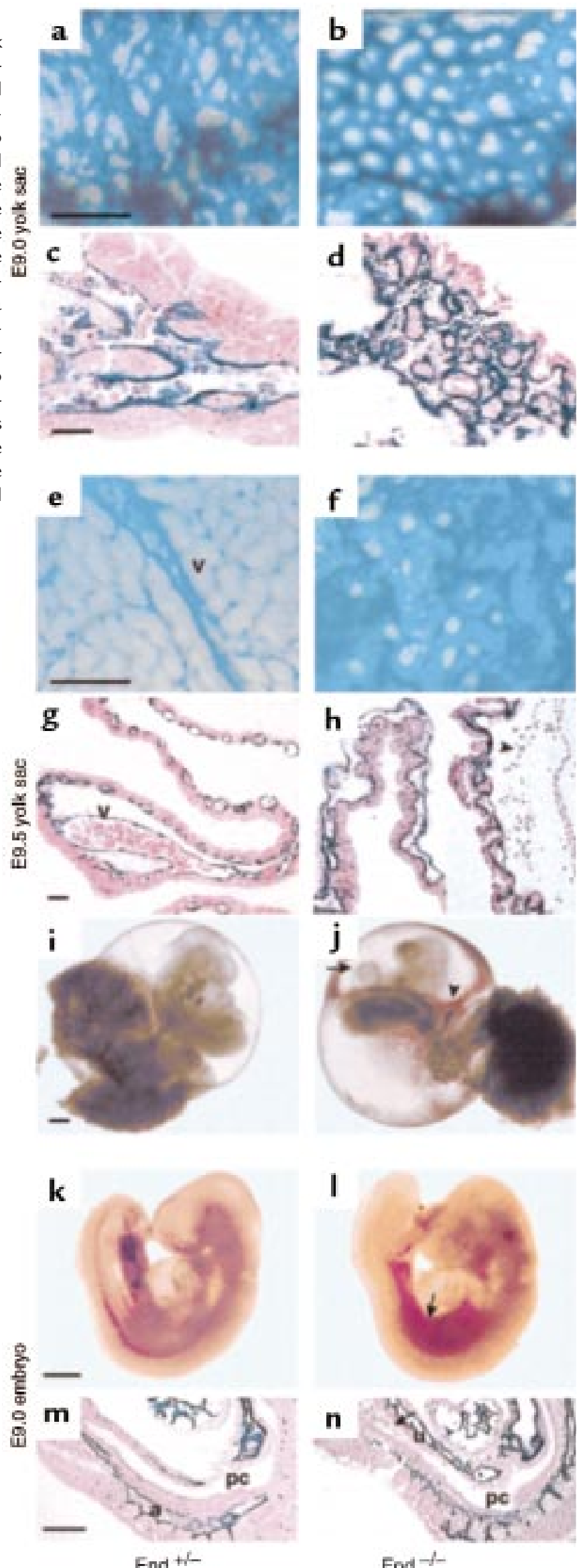

End ${ }^{-1-}$ 
values were normal for 20 dark-coat color C57BL/ $6 \mathrm{End}^{+/-}$ male (58-70) and female (49-63) mice tested.

An ear telangiectasia in the 129/Ola End ${ }^{+} /-$affected male 55.5 is shown in Figure 5. Direct microscopic examination of ear biopsies showed large dilated vessels at the periphery of the ear lobe, not seen in the normal control mice (Figure 6, a and b). These small vascular lesions generally lasted for 2-3 days and then ruptured and bled, often leading to partial ear necrosis. The $\beta$-gal-stained sections revealed the presence of abnormally dilated vessels, much larger than the capillaries seen normally in the ear (Figure $6, c$ and d). One such dilated vessel corresponding to a telangiectasia is shown at higher magnification along with several normal capillaries (Figure 6e). Female 102.6, progeny of male 55.5, showed several tail telangiectases and tail bleeding, frequent nosebleeds, and slower development, and died at 7 weeks.

\section{Discussion}

The endoglin promoter-driven expression of $\beta$-gal activity allowed us to establish that endoglin is expressed normally on the endothelium of End ${ }^{-/-}$embryos and extraembryonic structures, such as yolk sac and placenta, until E9.0. This implies that in situ differentiation of endothelial cells from mesodermally derived precursors, their assembly into the primary capillary network of yolk sac, placenta, and embryo, and the generation of primitive vessels connected to the primordia of the heart do not require endoglin. These early steps of vasculogenesis are thus nor- mal. Vascular development then includes proliferation and migration of endothelial cells that lead to growth and remodeling of the initially homogeneous capillary network by branching to form small and large vessels (19). Our results suggest that endoglin plays an important role in these angiogenic processes.

The primary capillary plexus of the yolk sac expressed endoglin as detected by $\beta$-gal activity. In the End ${ }^{-/}$yolk sacs, the blood islands at E9.0-9.5 dilated and fused to generate abnormal and irregular channels that lysed and released their primitive erythroblasts into the yolk sac cavity; the normal vitelline vessels were not formed. Li et al. (20) have observed that End ${ }^{-/-}$embryos died in utero at E11.5 and that no large vessels were observed in the yolk sac. It was suggested that angiogenesis was defective because of a scarcity of vascular smooth muscle cells in yolk sac and embryonic vessels occurring before the cardiogenesis defects, which were not described (20). These mice, like ours, were crossed into C57BL/6, but the ES cells were of 129/SVJ origin rather than 129/Ola. Although these 2 strains are highly related, this might explain the delayed phenotype observed in their studies. In our case, both yolk sac and heart defects were observed simultaneously at E9.0, and all mice died by E10.0-10.5.

Contact between endothelial and mesenchymal cells in a developing vessel was proposed to activate TGF- $\beta 1$, which induces differentiation of mesenchymal cells into pericytes and smooth muscle cells, stabilizing the endothelial tubes (21). Mice deficient in TGF- $\beta_{1}$ or T $\beta$ RII

\section{Figure 4}

Heart deficiency in End ${ }^{-1-}$ mice. Transverse sections from whole-mount embryos stained for $\beta$-gal activity are shown. The E9.0 $\mathrm{End}^{+/-}$embryo shows staining associated with the endocardium in the ventricular compartment $(v)$ and tightly delineated in the atrioventricular region (av). The endocardium of the End ${ }^{-1-}$ embryo is rudimentary, with an abnormally large lumen in the common atrial chamber (a) and the bulbus cordis (b). At E9.5 increased trabeculation is observed in the ventricle of the End ${ }^{+/-}$embryo; a few $\beta$-gal-stained mesenchymal cells (arrowhead) are seen adjacent to the atrioventricular canal. The heart of the End ${ }^{-1-}$ embryo is much larger than that of the control and is devoid of trabeculae; mesenchymal cells are absent. At E10.5 cushion-tissue mesenchyme (arrowhead) from the $E n d^{+/-}$embryo stains strongly positive for $\beta$-gal; in contrast, the heart of the End ${ }^{-1-}$ embryo shows edema and signs of necrosis. Bar: $100 \mu \mathrm{m}$.

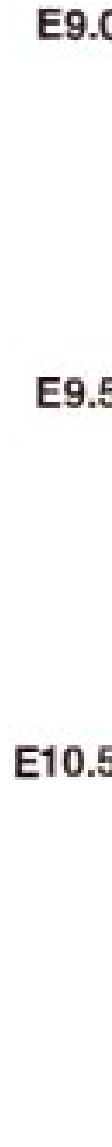

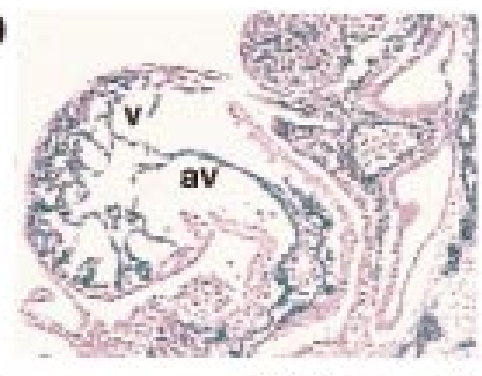
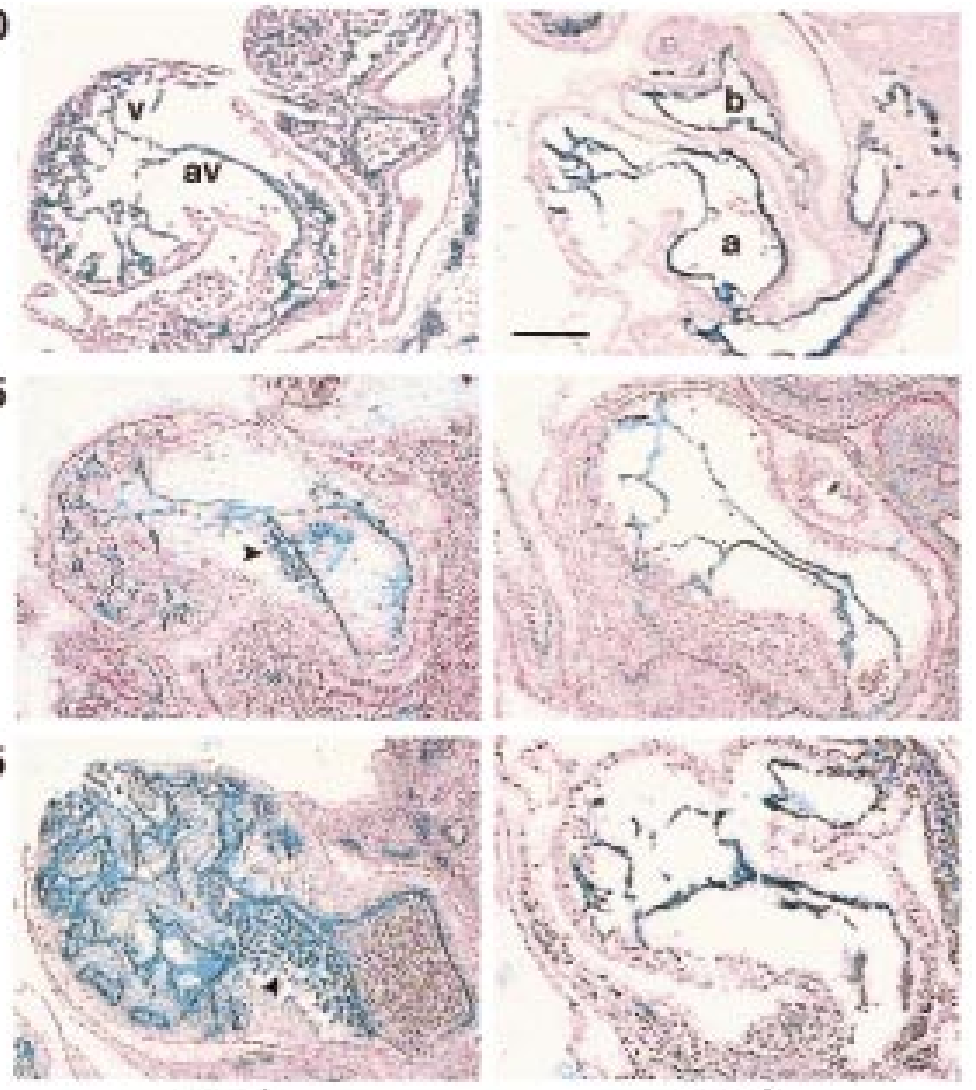

End + -

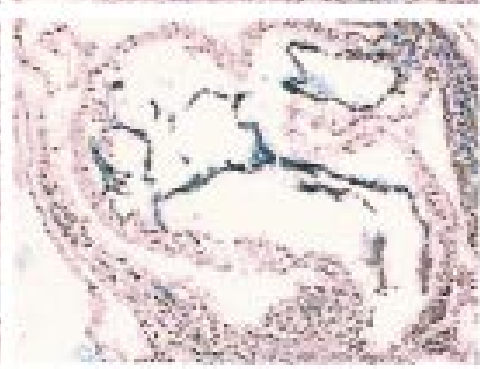

End ${ }^{-}$ 

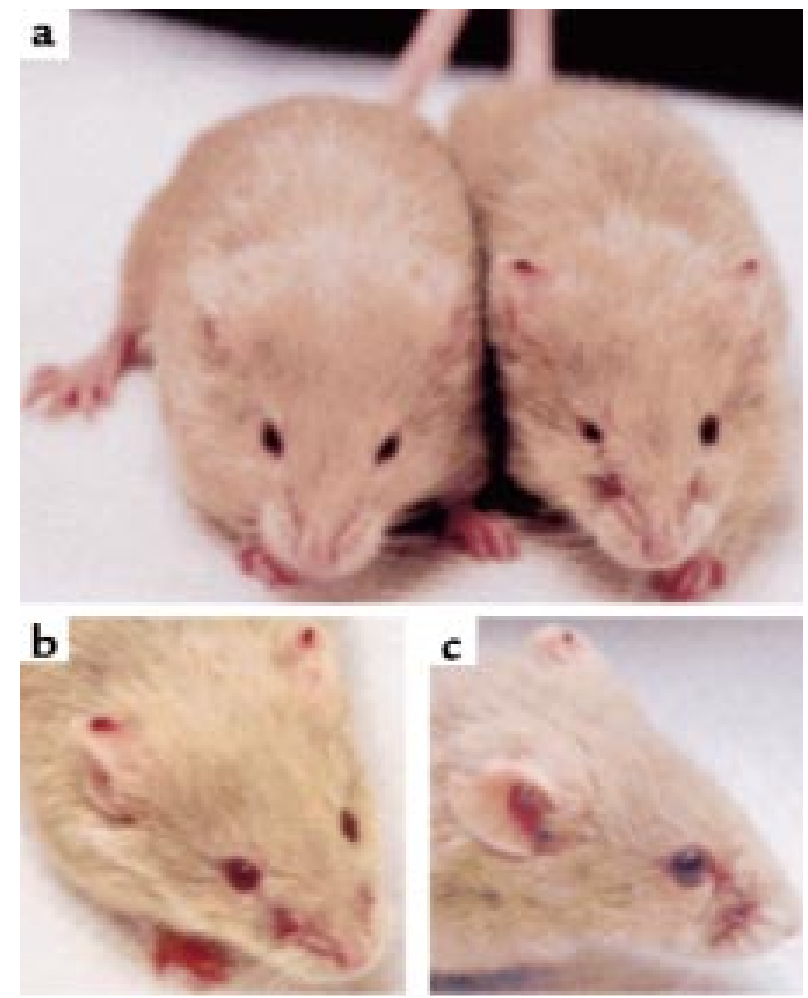

\section{Figure 5}

End $^{+/-}$129/Ola mice have nosebleeds and telangiectases characteristic of HHT. (a) A 129/Ola End $/$ - male mouse with recurrent nosebleeds and telangiectases is shown on the right of a female littermate with no disease manifestation. (b) Telangiectases are present on the upper part of both ears. (c) A side view provides a closer look at the affected nasal area.

die at E10.5 of an inadequate yolk sac capillary network showing poor adhesiveness between endothelial and mesothelial layers $(22,23)$. In vitro and in vivo mosaic studies with $\mathrm{End}^{-/-}$cells will be required to assess whether the impaired structural integrity of vessels is endothelial cell-autonomous or due to lack of production of PDGF$B$, for example, required to recruit pericytes $(21,24,25)$.

Angiopoietin-1 and its endothelial receptor, TIE$2 / \mathrm{TEK}$, are also implicated in regulation of interactions between endothelial and mesenchymal cells and their extracellular matrix $(18,26-28)$. Embryos deficient in TIE-2, with a related but distinct phenotype from those lacking endoglin, die at E9.5-E10.5. Endothelial cell number in the yolk sac of TIE-2/- embryos is reduced, whereas it is normal in End ${ }^{-/-}$embryos; both mutants show distended vascular channels, lack of vitelline vessels, hemorrhaging, and arrested heart development. An activating mutation of human TIE-2 tyrosine kinase leads to venous malformations, composed of dilated serpiginous channels with a variable thickness of smooth muscle cells (29). In HHT telangiectases start as dilated postcapillary venules that eventually fuse with arterioles and show disorganized smooth muscle cells (30). Thus, endoglin and TIE- 2 might have complementary roles in regulating cellular interactions in the vessel wall.

The pattern of endoglin expression in the developing heart was very striking and allowed us to visualize the endothelial-mesenchymal transformation in the region of the atrioventricular canal, because both cell types express endoglin. Endoglin is present on the endocardium throughout human heart development and is also transiently upregulated on cushion tissue mesenchyme of both the atrioventricular canal and the outflow tract at 5-8 weeks of gestation, suggesting an important role in valve formation and heart septation (31). TGF$\beta_{1}$-deficient mice also show abnormal heart development at E10.5 $(22,32)$. All 3 isoforms of TGF- $\beta$, and T $\beta$ RII, have been implicated in cushion-tissue formation in vitro (33-36). Endoglin is detected on chicken mesenchymal cells undergoing transformation and migrating into the cushion tissue, closely following the expression of the TGF- $\beta 3$ isoform (37). It was proposed that betaglycan might be the component of the TGF- $\beta$ receptor system responsible for endocardial cell trans-
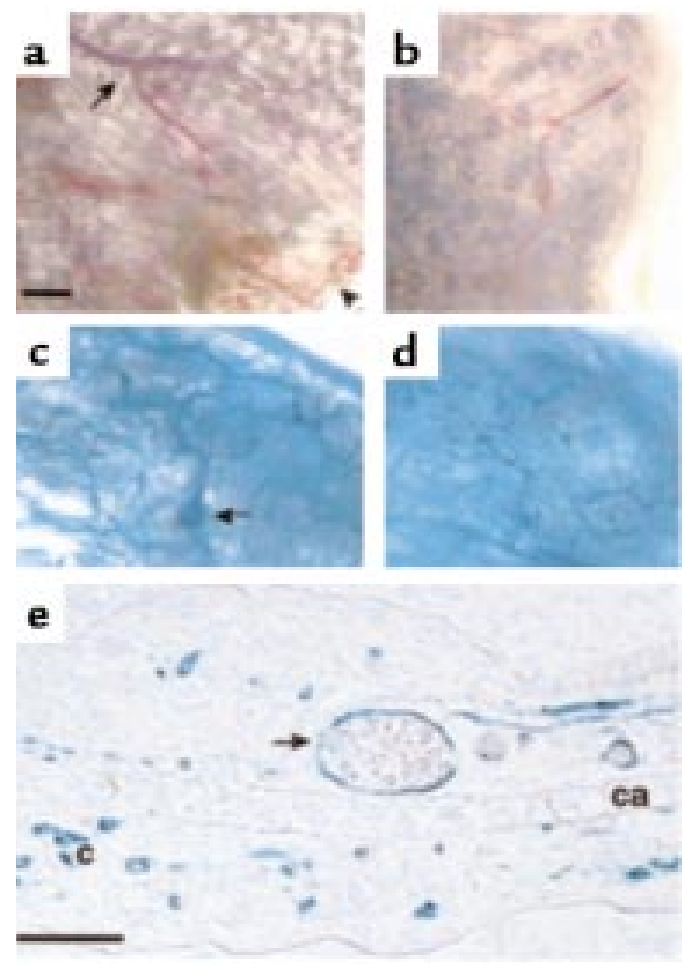

\section{Figure 6}

Microscopic examination of a telangiectasia from a 129/Ola End+mouse. Ear lobe biopsies from an End ${ }^{+/-}$mouse and normal littermate were left unstained ( $\mathbf{a}$ and $\mathbf{b}$ ) or were stained for $\beta$-gal activity (c and d). (a) A dilated vessel (arrow), engorged with blood, is seen in the affected End ${ }^{+/}$ear lobe, together with a necrotic area (arrowhead) from a telangiectasia ruptured previously. (b) The corresponding area from a nonaffected control 129/Ola mouse shows much smaller vessels. (c) A small telangiectasia (arrow), close to the edge of the affected ear, appears as a dilated vessel distinct from the adjacent network of capillaries. (d) Normal capillary network from a nonaffected ear. (e) A cross-section of the resected ear segment from the affected 129/Ola End ${ }^{+/-}$mouse was stained for $\beta$-gal. An enlarged vessel filled with blood (arrow), corresponding to a telangiectasia, is seen. The endothelial cells of this vessel and of several normal small capillaries are stained; a layer of cartilage (ca) is seen across the section. Bar: $500 \mu \mathrm{m}(\mathbf{a}-\mathbf{d})$ and $100 \mu \mathrm{m}(\mathbf{e})$. 
formation (38). However, our previous work on embryonic human hearts and the data presented here collectively suggest that endoglin is essential for heart valve formation and septation.

Disease manifestations were observed in some mice expressing a single copy of End, confirming that HHT1 is associated with a loss of function of the mutated allele (8). Our observations that 13 out of 20 mixed C57BL/6-129/Ola with light coat color and 5 out of 10 129/Ola End $\mathrm{EN}^{+/}$inbred mice showed clinical signs of HHT suggest that disease is associated with the 129/Ola background. This association implies that other gene(s) are contributing to the severity and heterogeneity of HHT. In the 129/Ola background, one such gene might be linked to coat color. It has been reported that 70-80\% of 129/Ola inbred mice have dramatic alterations in liver and lung vasculature, such as portal shunting and reduction and truncation of peripheral vessels, compared with C57BL/ 6 and CBA/Ca mice $(39,40)$. This phenotype might predispose mice with a single End copy to express HHT manifestations. The identification of modifier genes in the 129/Ola background is critical to our understanding of this complex vascular disorder and its underlying pathology.

The absence of clinical manifestations in half of 129/Ola End ${ }^{+/-}$mice and variation in age of onset and frequency of nosebleeds and telangiectases resemble the human disease, with heterogeneity even within a family. This suggests that epigenetic factors such as environment, blood pressure, oxygenation, shear forces, and hormonal levels must influence clinical manifestations (41). More detailed analysis of a large number of affected $\mathrm{End}^{+/-}$mice might reveal severe complications of HHT1, such as pulmonary, hepatic, and/or cerebral AVM. Monitoring these vascular malformations by emerging techniques such as magnetic resonance (MR) microscopy (42) would give us a better understanding of their origin and progression.

Our studies demonstrate that endoglin plays a crucial role in vascular and cardiovascular development because its absence leads to death of murine embryos in utero at E10.0-10.5. Further analysis of endothelial and mesenchymal cells isolated from End ${ }^{-/-}$mice might allow us to identify the precise role of endoglin in modulating effects of TGF- $\beta_{1}$ and other members of this superfamily on blood vessel and heart development. A murine form of HHT was generated by ablating the expression of a single End allele, confirming that haploinsufficiency leads to this disorder. The observations that the 129/Ola background is more susceptible to disease suggest that additional genes contribute to this complex vascular disorder. This mouse model will be invaluable in understanding the underlying pathophysiology of HHT and in testing potential therapeutic strategies.

\section{Acknowledgments}

We would like to thank W. Khoo, R. Sarao, M. Bissaseur, and N. Chan for their expert technical assistance, L. Morikawa for invaluable help in preparing sec- tions from embryos, and the staff of the animal colony at the Ontario Cancer Institute. This research was supported by grant NA3434 from the Heart and Stroke Foundation of Ontario (to M. Letarte) and by grants from the Medical Research Council of Canada (to M. Letarte and D.J. Dumont). A. Bourdeau is recipient of a studentship from the Medical Research Council of Canada, and M. Letarte is a Terry Fox Research Scientist of the National Cancer Institute of Canada.

1. Guttmacher, A.E., Marchuk, D.A., and White, R.I.J. 1995. Hereditary hemorrhagic telangiectasia. N. Engl. J. Med. 333:918-924.

2. McAllister, K.A., et al. 1994. Endoglin, a TGF- $\beta$ binding protein of endothelial cells is the gene for hereditary haemorrhagic telangiectasia type 1. Nat. Genet. 8:345-351.

3. Heutink, P., et al. 1994. Linkage of hereditary haemorrhagic telangiectasia to chromosome $9 \mathrm{q} 34$ and evidence for locus heterogeneity. J. Med. Genet. 31:933-936.

4. McAllister, K.A., et al. 1994. Genetic heterogeneity in hereditary haemorrhagic telangiectasia: possible correlation with clinical phenotype. $J$. Med. Genet. 31:927-932.

5. Porteous, M.E.M., et al. 1994. Genetic heterogeneity in hereditary haemorrhagic telangiectasia. J. Med. Genet. 31:925-926.

6. Berg, J.N., Guttmacher, A.E., Marchuk, D.A., and Porteous, M.E.M. 1996. Clinical heterogeneity in hereditary haemorrhagic telangiectasia: are pulmonary arteriovenous malformations more common in families linked to endoglin? J. Med. Genet. 33:256-257.

7. Johnson, D.W., et al. 1996. Mutations in the activin receptor-like kinase 1 gene in hereditary hemorrhagic telangiectasia type 2. Nat. Genet. 13:189-195

8. Pece, N., et al. 1997. Mutant endoglin in hereditary hemorrhagic telangiectasia type I is transiently expressed intracellularly and is not a dominant negative. J. Clin. Invest. 100:2568-2579.

9. Shovlin, C.L., Hughes, J.M.B., Scott, J., Seidman, C.E., and Seidman, J.G. 1997. Characterization of endoglin and identification of novel mutations in hereditary hemorrhagic telangiectasia. Am. J. Hum. Genet. 61:68-79.

10. Gougos, A., and Letarte, M. 1988. Identification of a human endothelial cell antigen with monoclonal antibody $44 \mathrm{G} 4$ produced against a pre-B leukemic cell line. J. Immunol. 141:1925-1933.

11. Letarte, M., Greaves, A., and Vera, S. 1995. CD105 (endoglin) cluster report. In Leukocyte typing V: white cell differentiation antigens. S.F. Schlossman et al., editors. Oxford University Press. Oxford, United Kingdom. $1756-1759$.

12. St.-Jacques, S., Cymerman, U., Pece, N., and Letarte, M. 1994. Molecular characterization and in situ localization of murine endoglin reveal that it is a transforming growth factor- $\beta$ binding protein of endothelial and stromal cells. Endocrinology. 134:2645-2657.

13. Cheifetz, S., et al. 1992. Endoglin is a component of the transforming growth factor- $\beta$ receptor system in human endothelial cells. J. Biol. Chem. 267:19027-19030.

14. Letamendia, A., et al. 1998. Role of endoglin in cellular responses to transforming growth factor- $\beta$. A comparative study with betaglycan. $J$. Biol. Chem. 273:33011-33019.

15. Pece, B.N., Wrana, J., and Letarte, M. 1999. Endoglin is an accessory protein that interacts with the signaling receptor complex of multiple members of the transforming growth factor- $\beta$ superfamily. J. Biol. Chem. 274:584-594.

16. Lastres, P., et al. 1996. Endoglin modulates cellular responses to TGF- $\beta_{1}$. J. Cell Biol. 133:1109-1121.

17. Caniggia, I., Taylor, C.V., Ritchie, J.W.K., Lye, S.J., and Letarte, M. 1997. Endoglin regulates trophoblast differentiation along the invasive pathway in human placental villous explants. Endocrinology. 138:4977-4988.

18. Puri, M.C., Rossant, J., Alitalo, K., Bernstein, A., and Partanen, J. 1995. The receptor tyrosine kinase TIE is required for integrity and survival of vascular endothelial cells. EMBO J. 14:5884-91.

19. Risau, W. 1997. Mechanisms of angiogenesis. Nature. 286:671-674.

20. Li, D.Y., et al. 1999. Defective angiogenesis in mice lacking endoglin. Science. 284:1534-1537.

21. Folkman, J., and D'Amore, P.A. 1996. Blood vessel formation: what is its molecular basis? Cell. 87:1153-1155.

22. Dickson, M.C., et al. 1995. Defective haematopoiesis and vasculogenesis in transforming growth factor- $\beta 1$ knock out mice. Development. 121:1845-1854.

23. Oshima, M., Oshima, H., and Taketo, M.M. 1996. TGF- $\beta$ receptor type II deficiency results in defects of yolk sac hematopoiesis and vasculogenesis. Dev. Biol. 179:297-302.

24. Lindahl, P., Johansson, B.R., Leveen, P., and Betsholtz, C. 1997. Pericyte 
loss and microaneurysm formation in PDGF-B-deficient mice. Science. 277:242-245

25. Hellström, M., Kalén, M., Lindhal, P., Abramsson, A., and Betsholtz, C. 1999. Role of PDGF-B and PDGFR- $\beta$ in recruitment of vascular smooth muscle cells and pericytes during embryonic blood vessel formation in the mouse. Development. 126:3047-3055.

26. Suri, C., et al. 1996. Requisite role of angiopoietin-1, a ligand for the TIE2 receptor, during embryonic angiogenesis. Cell. 87:1171-1180.

27. Dumont, D.J., et al. 1994. Dominant-negative and targeted null mutations in the endothelial receptor tyrosine kinase, tek, reveal a critical role in vasculogenesis of the embryo. Genes Dev. 8:1897-1909.

28. Sato, T.N., et al. 1995. Distinct roles of the receptor tyrosine kinases Tie1 and Tie- 2 in blood vessel formation. Nature. 376:70-74.

29. Vikkula, M., et al. 1996. Vascular dysmorphogenesis caused by an activating mutation in the receptor tyrosine kinase TIE2. Cell. 87:1181-1190.

30. Braverman, I.M., Keh, A., and Jacobson, B.S. 1990. Ultrastructure and three-dimensional organization of the telangiectases of hereditary hemorrhagic telangiectasia. J. Invest. Dermatol. 95:422-427.

31. Qu, R., Silver, M.M., and Letarte, M. 1997. Distribution of endoglin in early human development reveals high levels on endocardial cushion tissue mesenchyme during valve formation. Cell Tissue Res. 292:323-343.

32. Letterio, J.J., et al. 1994. Maternal rescue of transforming growth factor$\beta 1$ null mice. Science. 264:1936-1938.

33. Akhurst, R.J., Dickson, M., and Millan, F.A. 1994. Transforming growth factor $\beta$ s and cardiac development. In Growth factors and the cardiovascular system. P. Cummins, editor. Kluwer Academic Publishers. Boston, MA. 347-366
34. Potts, J.D., Dagle, J.M., Walder, J.A., Weeks, D.L., and Runyan, R.B. 1991. Epithelial-mesenchymal transformation of embryonic cardiac endothelial cells is inhibited by a modified antisense oligonucleotide to transforming growth factor $\beta 3$. Proc. Natl. Acad. Sci. USA. 88:1516-1520.

35. Runyan, R.B., Potts, J.D., and Weeks, D.L. 1992. TGF- $\beta 3$-mediated tissue interaction during embryonic heart development. Mol. Reprod. Dev. 32:152-159.

36. Brown, C.B., Boyer, A.S., Runyan, R.B., and Barnett, J.V. 1996. Antibodies to the type II TGF- $\beta$ receptor block cell activation and migration during atrioventricular cushion transformation in the heart. Dev. Biol. 174:248-257.

37. Vincent, E.B., Runyan, R.B., and Weeks, D.L. 1998. Production of the transforming growth factor- $\beta$ binding protein endoglin is regulated during chicken heart development. Dev. Dyn. 213:237-247.

38. Brown, C.B., Boyer, A.S., Runyan, R.B., and Barnett, J.V. 1999. Requirement of type II TGF- $\beta$ receptor for endocardial cell transformation in the heart. Science. 283:207-209.

39. Elsaghier, A.A.F., and McLaren, D.J. 1989. Schistosoma mansoni: evidence that vascular abnormalities correlate with the "non-permissive" trait in 129/Ola mice. Parasitology. 99:377-81.

40. Coulson, P.S., and Wilson, R.A. 1989. Portal shunting and resistance to Schistosoma mansoni in 129 strain mice. Parasitology. 99:383-89.

41. Shovlin, C., and Letarte, M. 1999. Hereditary hemorrhagic telangiectasia and pulmonary arteriovenous malformations: Issues in clinical management and review of pathogenic mechanisms. Thorax. 54:714-729.

42. Smith, B.R. 1999. Visualizing human embryos. Sci. Am. 280:76-81. 